\title{
Assessing impact of weather variability and changing climate on oil-palm yield in major growing regions of southern Thailand
}

\section{RAWEE CHIARAWIPA*, KANJANA THONGNA and SAYAN SDOODEE}

\author{
Department of Plant Science, Faculty of Natural Resources, Prince of Songkla University, Songkhla, 90112, Thailand \\ *Corresponding author: rawee.c@psu.ac.th
}

\begin{abstract}
Oil palm yield is very responsive to weather fluctuations in the growing season. The purpose of this study was to investigate the relationship between yield variation and climate trends in the major oil palm-growing regions, especially in Southern Thailand (Chumphon; CP, Ranong; RN, Krabi; KB, Trang; TR, Satun; ST, Phang-Nga; PN, SuratThani; SR and Nakhon Si Thammarat; NS) where oil palm has been grown in a large plantation. Monthly weather variables from 16 agricultural meteorological stations were analyzed by linear and non-linear regressions over 28 years in each major oil palm-producing region. To evaluate the trends of changes in weather parameters and yield, a statistical model was developed for estimating oil palm yield based on climatic trends during 1994-2017. The results showed that warming trends were observed at all major oil palm-growing regions. There were pieces of evidence of significant correlation in temperature trends which had the strongest values in $K B\left(T_{\max }, R^{2}=0.534^{* *}\right)$ and $P N\left(T_{\text {min }}\right.$, $\left.\mathrm{R}^{2}=0.670^{* *}\right)$. The highest trends of $E T$ and $\mathrm{RH}$ were also markedly increased in $\mathrm{SR}\left(\mathrm{R}^{2}=0.618^{* *}\right)$. Whereas precipitation trend had slightly increasing changes in CP $\left(R^{2}=0.220^{* *}\right)$ and $P N\left(R^{2}=0.233^{* *}\right)$. In addition, the annual trends in the values of Heliothermal Index, Dryness Index and Cool Night Index were markedly increased in NS, RN and KB, respectively. Comparing climate variables and yield variations over 19 years, the study indicated that the relationships between observed yield and estimated yield had highly significant differences in CP $\left(R^{2}=0.468^{* *}\right)$, SR $\left(R^{2}=0.735^{* * *}\right)$ and $N S\left(R^{2}=0.579^{* * *}\right)$, but there was lower value in $K B\left(R^{2}=0.098^{*}\right)$ than those of the other regions. Therefore, this study indicates that recent climate trends have had an implicit effect on oil palm yield in the major producing regions in Southern Thailand. This study could be a guideline to further planning for oil palm management.
\end{abstract}

Key words: Yield variation, plant climate model, phenotypic plasticity, phenology

Globally, the 2010s has been the warmest decade of the last 1,000 years making it apparent that climate change is a reality (Bal and Minhas, 2017). In years 1921-1984, mean temperatures for the Northern hemisphere were about $0.4^{\circ} \mathrm{C}$ warmer than those prevailing in years 1851-1920 (Jones et al., 1986). Several researches in many regions have reported increasing surface temperature trends in recent decades such as in the arid and semi-arid tropics (Sivakumar et al., 2005), humid and sub-humid tropics (Zhao et al., 2005) and temperate regions (Maracchi et al., 2005). Global temperature is now about $0.6^{\circ} \mathrm{C}$ greater than the $1900 \mathrm{~s}$ and may be up to $4{ }^{\circ} \mathrm{C}$ greater by 2100 . Warming is shrinking winter snow and decreasing ice cover. Extreme rain and flooding may increase in some areas but may decrease in others (IPCC, 2007). Many countries in Asia, the warming trends over India have been reported to be about $0.57^{\circ} \mathrm{C}$ per 100 years (Kumar et al., 1994). For instance, the increase in average temperature ranges from $0.4-0.7^{\circ} \mathrm{C}$ decade in China (Liu et al., 2010). Overland regions of Asia, the projected area-averaged annual mean warming is likely to be $1.6 \pm 0.2$ ${ }^{\circ} \mathrm{C}$ in the $2020 \mathrm{~s}, 3.1 \pm 0.3{ }^{\circ} \mathrm{C}$ in the $2050 \mathrm{~s}$, and $4.6 \pm 0.4{ }^{\circ} \mathrm{C}$ in the 2080s (Sivakumar et al., 2005).

At present, climate change has already affected crop productivity in many regions over Southeast Asia and the South Pacific region which has increased $0.5-0.7^{\circ} \mathrm{C}$ during the past 50 years and suffering serious damage from El Niño and La Niña events, especially in Indonesia, Vietnam, Laos and Cambodia (Ministry of the Environment (Japan), 2014). In Thailand, it has been observed that positive annual temperature trends can be detected in a range of 0.12-0.59 ${ }^{\circ} \mathrm{C} /$ decade in the North, Northeast and Southern regions of Thailand (Limsakul et al., 2010b). Moreover, some positive and negative precipitation trends as related to El Niño/ Southern Oscillation phenomenon can be altered patterns along the coast of peninsular Thailand (Limsakul et al., 2010a) and Mekong delta area, Vietnam (Lee and Dang, 2018). 
Conspicuous climate change has affected crop plant development and adaptation in a number of studied reports over a 50-year period. Their impacts are particularly becoming more discriminating than ever on phenological and yield changes of fruit trees (Chmielewski et al., 2004), flower species (Miller-Rushing and Inouye, 2009) and other field crops (Tao et al., 2006). Furthermore, climate factors may not only act upon yield variation but also on its quality. The distribution of globally averaged surface temperature shows that the warming observed temperature has affected in the mid to high Northern Hemisphere latitudes. Particularly in winter months, temperatures have warmed more rapidly than those in summer months. Furthermore, nighttime temperatures are more affected than day time temperatures (Salinger, 2005). Oil palm is one of the most valuable plantation crops in Thailand which has been a rapid expansion of domestic and has risen into the world's top 3 producing countries (Index Mundi, 2019). In 2018, the annual yield was in excess of 14 million metric tons and the plantation area covered over 0.90 million hectare. Oil palmproducing regions are grown in all of Thailand's regions, but most of the plantations are located in the Southern part (80\%). Moreover, the eight leading provinces that contribute more than two-thirds of the total oil palm production are in Southern Thailand (Office of Agricultural Economics, 2018). Almost oil palms grown in tropical climates consume more rainfalls. Weather is a critical determinant of yield quantity which is determined by chronological order, floral sex determination, and fresh bunch development (Corley and Tinker, 2003). Accordingly, climate change affects on oil palm phenology and fruit production. Oil palm yield is responded markedly to climate variation in the growing season which is very responsive to rainfall fluctuations in growing seasonal variation (Oettli et al., 2018). Moreover, rainfall is considered as an important factor influencing the quality of oil content and fatty acid composition (Mhanhmad et al., 2011). In the Southern region, altered precipitation patterns are also anticipated with the occurrence of rainfall values, monitoring in amount, and frequency over the past 20 years (Unjan et al., 2017). The pattern of precipitation has also changed (Sdoodee, 2007) caused by climate change more than 30 years ago which can be problems with a frequency of droughts during some growing seasons, especially in Southern Thailand (Apiratikorn et al., 2014).

In addition, the effects of weather variability on yield components are complex. Several reports have mentioned that climate change continues to have a major impact on crop productivity all over the world (Lobell and Burke,
2010). The statistical model is now widely used to predict oil palm yield that responds to climate change related to El Niño and La Niña events in the different developmental stages of the fruit bunch (Cadena et al., 2006). However, climate and yield models are often suitable and characterized by local region for decision-making.

Thus, observing the relationship between yield variation and climate trends in the major oil palm-growing regions in Thailand has become increasingly important. The purpose of this study was trying to investigate the relationship between observed yield and estimated yield anomalies in order to be able to evaluate the probable and simply possible consequences for the impact of climate change in major oil palm-growing regions in Southern Thailand.

\section{MATERIALS AND METHODS}

\section{Climate data in the major oil palm regions}

The meteorological data were collected from 16 agricultural meteorological stations which located in the major oil palm-growing regions in Southern Thailand (Chumphon; CP, Ranong; RN, Krabi; KB, Trang; TR, Satun; ST, Phang-Nga; PN, SuratThani; SR and Nakhon Si Thammarat; NS) where oil palm has been grown in a large plantation. Then monthly climate variables for over 28 years in each major oil palm-producing region from those stations were analyzed by linear and non-linear regressions. Also, monthly datasets of air temperature (maximum temperature (Tmax), minimum temperature (Tmin) and mean temperature (Tmean)), rainfall (ppt), evapotranspiration (ET), and relative humidity (RH) had been observed in order to detect the uncertainty of climate variations on seasonal and annual timescales during years 1986-2014.

\section{Multi-criteria climatic classification}

There were three complementing indices: the heliothermal index (HI), cool night index (CI), and dryness index (DI) that would be used as a research tool for classifying crop-growing regions (Tonietto and Carbonneau, 2004). Helio-thermal Index (HI). Calculating will be as:

$$
H I=\sum_{1.04}^{30.09} \frac{\left(T-T_{b}\right)+\left(T_{x}-T_{b}\right)}{2}(d)
$$

Where T was the mean daily temperature, Tx was the maximum daily temperature, $\mathrm{Tb}$ was the base temperature $\left(10^{\circ} \mathrm{C}\right)$, and $\mathrm{d}$ was a length of day coefficient. Under the HI system, climates were grouped into six classes by ranging from very cool $(\mathrm{HI}=1500)$, cool $\left(>1500<1800^{\circ} \mathrm{C}\right)$, warm 
$\left(>1800<2100^{\circ} \mathrm{C}\right)$ very warm $\left(>2100<2400{ }^{\circ} \mathrm{C}\right)$, hot $\left(>2400<3000^{\circ} \mathrm{C}\right)$, and very hot $(\mathrm{HI}>3000)$. Dryness Index (DI) data represent the value of soil moisture at the end of the growing season. Calculating was done by the following equation:

$$
D I=W_{o}+\sum_{01.04}^{30.09}\left(P-\left(E_{t}+E_{s}\right)\right)
$$

Where $\mathrm{W}_{0}$ was $200 \mathrm{~mm}$ of the initial soil moisture with representing the sum of monthly differences of precipitation (P), water loss through transpiration (Et) and evaporation from bare soil (Es). Using DI, the study would define four climates with varying from very dry (DI $\leq-100 \mathrm{~mm})$, dry $(<50>-100 \mathrm{~mm})$, mild humid $(<150>50 \mathrm{~mm})$, and high humid (DI $>150 \mathrm{~mm}$ ) (Tonietto and Carbonneau, 2004). Cool Night Index (CI) data describe the night temperatures during bunch development. Calculating was done by the following equation (Tonietto and Carbonneau, 2004):

$$
C I=\frac{1}{N} \sum_{1.09}^{30.09} T n
$$

Where $\mathrm{N}$ was the number of days in the month. Tn was the minimum daily temperature. CI defined four classes from very cool nights $\left(\mathrm{CI}=12^{\circ} \mathrm{C}\right)$, cool nights $\left(>12<14^{\circ} \mathrm{C}\right)$, warm nights $\left(>14<18^{\circ} \mathrm{C}\right)$, and very warm nights $\left(\mathrm{CI}>18^{\circ} \mathrm{C}\right)$.

\section{Oil palm yield data}

The data of oil palm yields and areas over the 28 years had been recorded in annual reports by the Office of Agricultural Economics (2018). Together, the percentages of oil palm yield changes were represented from the annual total yields and planting areas by 8 growing regions for estimating yield variations from years1994-2015. All measurement values can then be calculated and described by the following equations (1), (2), and (3):

$$
\begin{aligned}
& A_{r}=\sum_{i=1}^{n} A_{r, i} \\
& G_{r}=\sum_{i=1}^{n} G_{r, i} \\
& Y_{r}=\frac{G_{r, i}}{A_{r, i}}
\end{aligned}
$$

Where $A_{r}$ and $G_{r}$ were total area (converted to acre) and total yield product $(\mathrm{kg})$ in region r and year i. Additionally, $Y_{r}$ was the computed yield values by dividing the total product by total harvested area $(\mathrm{kg} / \mathrm{ac})$ in region $\mathrm{r}$ and year i. Therefore, yield changes ( $\%$ ) could be considered as an independent variable based on the time series in each year during 1997-2015.

\section{Yield estimation and statistical analysis}

Multiple regression was used to examine the relationship between climate variables and the previous 3year yield variations (in units of $\mathrm{Mg} / \mathrm{ha}$ ) (Shanmuganathan and Narayanan, 2012). The data of yield variation were calculated for each year and represented by the residuals of the detrended values. The independent regressions were analyzed between monthly yield residuals and monthly climate variables (Tmax, Tmin, Tmean, rainfall, ET, and RH) for each growing region. In addition, the significantly highest coefficient of determination $\left(\mathrm{r}^{2}\right)$ was selected as a polynomial equation in order to isolate climate factor from other yield impacts which ranged from January to December. Each predictor variable then was considered to select as an appropriate factor. Climate variables were used to analyze the estimated yield value with historical climate data by polynomial curve fitting from each year.

The relationship between climate and yield variables was developed and applied to observe all yield trends. All equations with high coefficient of determination $\left(\mathrm{R}^{2}\right)$ were assumed to represent a similar trend of yield. Thus, the relationship between climate variables and yield variations (\%) could be estimated by fitting a trend to yield time series over the years 1997-2015. The observed yield anomaly and estimated values were generally expressed over the 3 years (2015 to 2017) of yield prediction adapted and described in equation (4) or (5) (Lobell et al., 2007):

$$
\begin{aligned}
& Y_{r}=\beta_{0}+\beta_{1} T_{i}+\beta_{2} T_{i}^{2} \\
& Y_{r}=\beta_{0}+\beta_{l} X_{l}+\beta_{2} Z_{l}+\beta_{3} X_{l}^{2}+\beta_{4} Z_{l}^{2}+\varepsilon_{l}
\end{aligned}
$$

Where $Y_{r}$ was yield anomaly (\%) in $\mathrm{r}$ region, $\mathrm{X}$ were monthly climate variables (tmax, tmin, tmean, rainfall, ET and $\mathrm{RH}$ ) in month i, $\beta_{0, i}$ was an intercept in each climate variable to be estimated by regression, and $\varepsilon i$ was an error term of yield change.

\section{Statistical analysis}

All parameters of the linear and non-linear regressions were performed with statistic software to compare between observed yield and estimated yield anomalies over this study. Pearson's correlation analysis was used to examine the relationships of all parameters.

\section{RESULTS AND DISCUSSION}

\section{Trends of annual weather variables}

The annual average changes of Tmax, Tmin, Tmean, 

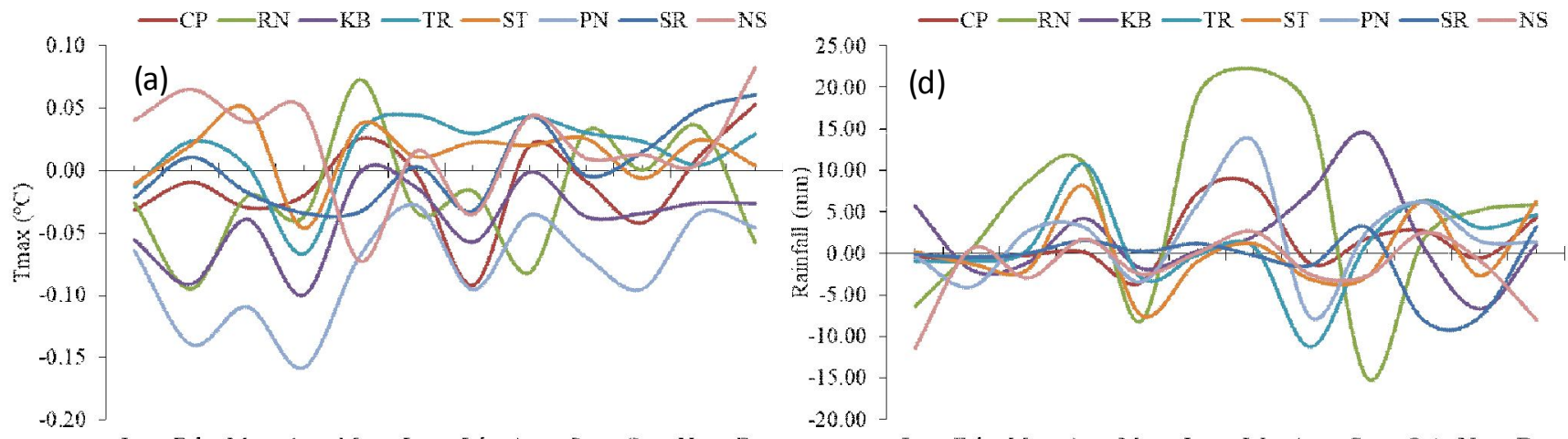

Jan Feb Mar Apr May Inu Jul Aug Sep On Nov Dee

Jan Feb Mar Ayr May Jus Jul Aug Sep oct Nor Dec
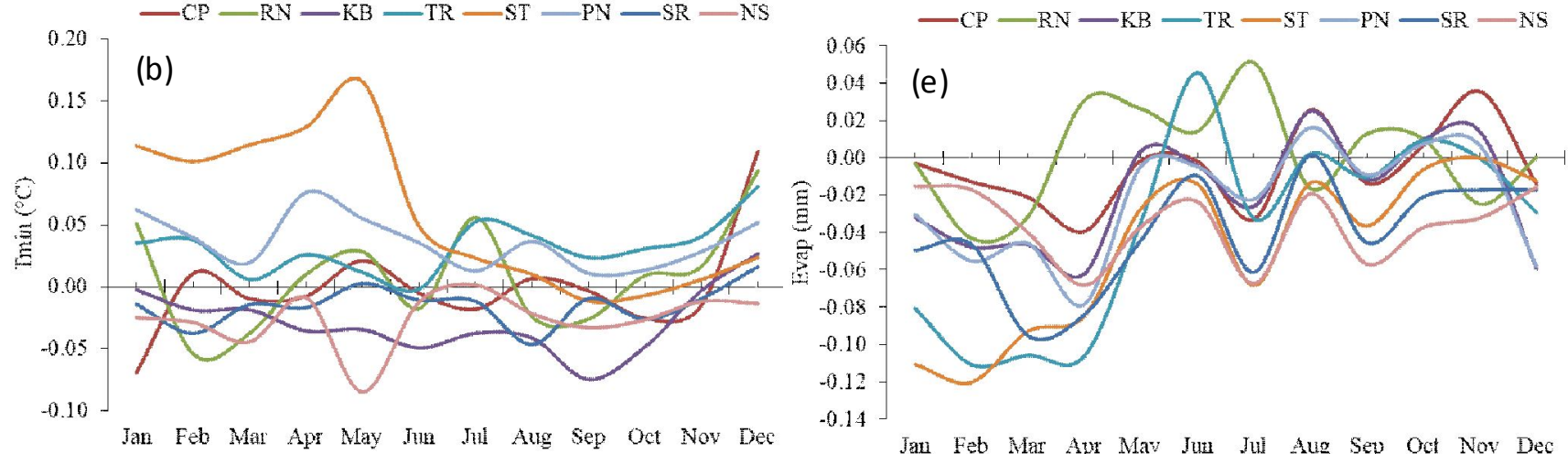

Jan Feb Mar Ayr May Jun Jul Aug Sep Oet Noy Dec
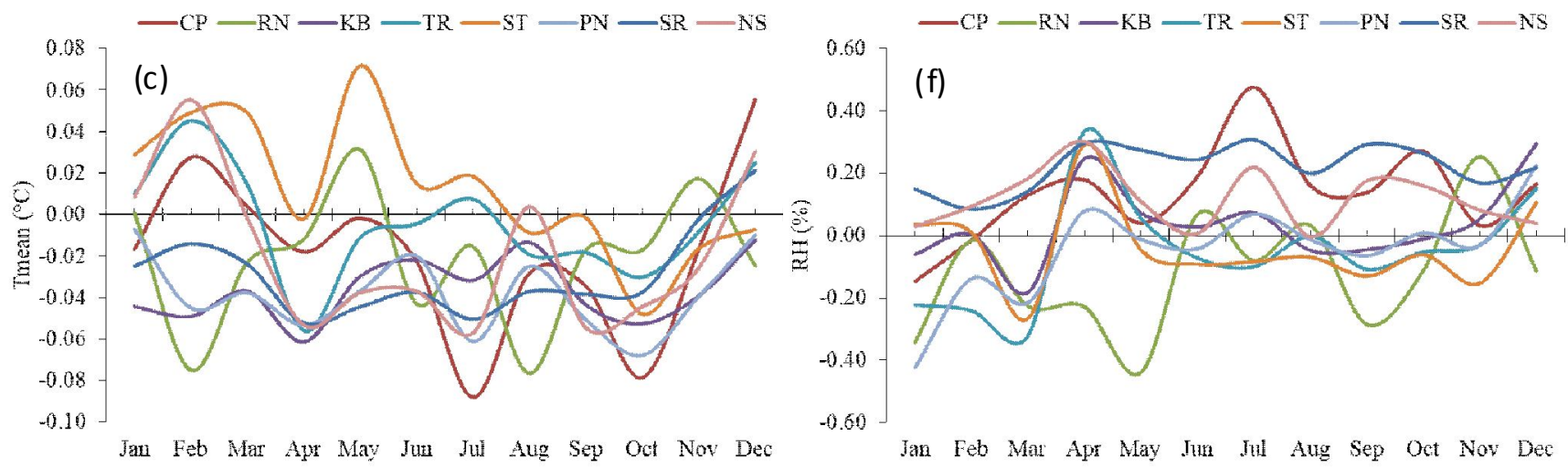

Fig. 1: Anomalies of monthly maximum temperature (Tmax) (a), minimum temperature (Tmin)(b), mean temperature (Tmean) (c), rainfall (d), evapotranspiration (ET) (e) and relative humidity (RH) (f) in provinces of Chumphon (CP), Ranong (RN), Krabi (KB), Trang (TR), Satun (ST), Phang-Nga (PN), Surat Thani (SR) and Nakhon Si Thammarat (NS) during 1986-2008

rainfall, ET and RH showed as the similarly fluctuated trends of all 8 locations during 1986-2014 (Table1). The significant increases in Tmin were recorded in $\mathrm{PN}\left(\mathrm{R}^{2}=0.670^{* *}\right)$, SR $\left(\mathrm{R}^{2}=0.392^{* *}\right), \mathrm{CP}\left(\mathrm{R}^{2}=0.363^{* *}\right), \mathrm{ST}\left(\mathrm{R}^{2}=0.210^{*}\right)$, and $\mathrm{TR}$ $\left(\mathrm{R}^{2}=0.196^{*}\right)$. In contrast, annual Tmax exhibited statistically significant decreasing trends in $\mathrm{RN}\left(\mathrm{R}^{2}=0.220^{*}\right), \mathrm{KB}$ $\left(\mathrm{R}^{2}=0.534^{* *}\right)$ and $\mathrm{PN}\left(\mathrm{R}^{2}=0.506^{* *}\right)$. The average increase of Tmax indicated the strongest trend in NS $\left(\mathrm{R}^{2}=0.306^{* *}\right)$. Significant decrease evapotranspiration (ET) values were markedly exhibited in $\mathrm{SR}\left(\mathrm{R}^{2}=0.618^{* *}\right)$ and $\mathrm{NS}\left(\mathrm{R}^{2}=0.612^{* *}\right)$ which were larger than those of ST $\left(\mathrm{R}^{2}=0.523^{* *}\right)$, PN $\left(\mathrm{R}^{2}=0.359^{* *}\right)$, and $\mathrm{TR}\left(\mathrm{R}^{2}=0.358^{* *}\right)$. On the other hand, rainfall (ppt) had general stable trends overall of the region even though the average increasing changes of ppt could be observed in $\mathrm{PN}\left(\mathrm{R}^{2}=0.233^{*}\right)$. Meanwhile, the average changes of RH had decreased to the highest trend in $\mathrm{RN}$ $\left(\mathrm{R}^{2}=0.244^{* *}\right)$ and $\mathrm{TR}\left(\mathrm{R}^{2}=0.196 *\right)$. However, positive trends in $\mathrm{SR}\left(\mathrm{R}^{2}=0.636^{* *}\right)$ and $\mathrm{NS}\left(\mathrm{R}^{2}=0.315^{* *}\right)$ were noted. 

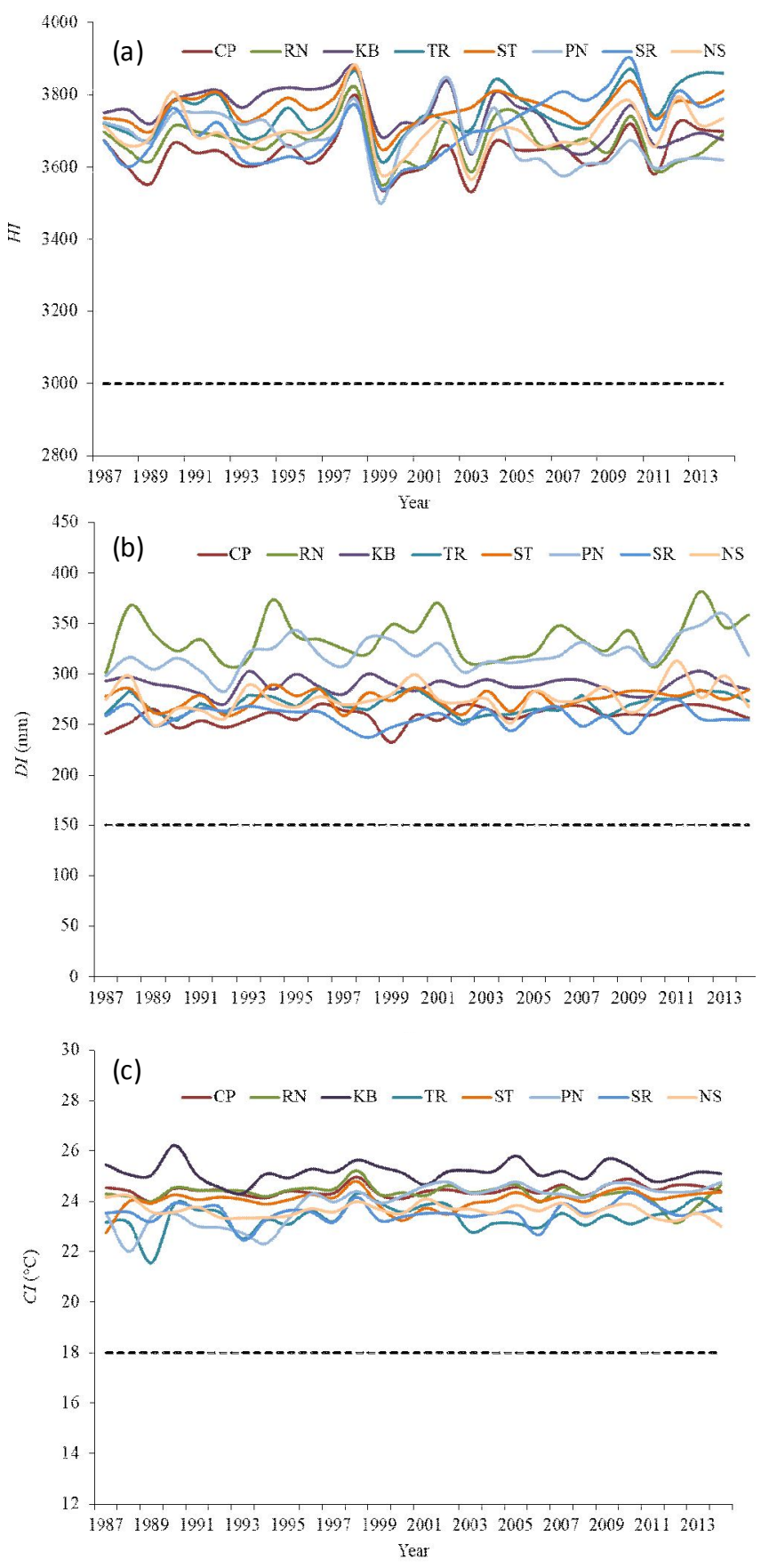

Fig. 2: Changes in Heliothermal Index (HI) (a), Dryness Index (DI) (b) and Cool Night Index (CI) (c) during years 1986-2014 for the 8 different oil palm regions (Chumphon; CP, Ranong; RN, Krabi; KB, Trang; TR, Satun; ST, Phang-Nga; PN, Surat Thani; SR, Nakhon Si Thammarat; NS)

\section{Trends of monthly weather variables}

Averages of monthly climates show similar trends of positive and negative anomalies for the 8 different regions (Fig. 1). Many positive changes of Tmax could be observed in February, March, May, June, August, September, November, and December. Monthly Tmax values indicated much warmer by $0.05^{\circ} \mathrm{C}$ in NS, TR and ST. Meanwhile, the lowest value was exhibited in PN. Average monthly Tmin in ST had gone up by $0.10^{\circ} \mathrm{C}$ and $0.16^{\circ} \mathrm{C}$ in January to May. However, the study found similar observing values from June to December for all regions. Additionally, average monthly ppt values were found to be the positive anomalies in March to April, June to July, and October to December detected in RN and PN around 05-25 $\mathrm{mm}$. Monthly evapotranspiration had greatly decreased from January to December detected in SR, NS and ST. However, there was a strong increasing trend in RN by 0.01 to $0.05 \mathrm{~mm}$ from April to July. Meanwhile, average monthly RH showed all positive values in SR that occurred from January to December. The highest values of RH frequently occurred in April observed in all regions.

\section{Growing season weather variables}

All growing season changes from years 1986-2014 or over 28 years were shown in Fig. 2. The annual trends of HI values ranged generally from $3500-3800{ }^{\circ} \mathrm{C}$ which the largest values were found in $\mathrm{KB}$ during years 1986-2000 (Fig. 2a). Changes in DI during the growing seasons were also expected which annual total value could increase generally by $240-360 \mathrm{~mm}$ with the significant increases found in RN and PN (Fig. 2b). CI could increase generally by $21-26^{\circ} \mathrm{C}$ with the highest increase found in $\mathrm{KB}$ (Fig. 2c).

\section{Relationships between weather variables and yield anomalies}

During the years 1994-2014 based on the relationships between climate data and yield anomaly, coefficients of determination $\left(\mathrm{R}^{2}\right)$ and adjusted $\mathrm{R}^{2}\left(\mathrm{R}_{\text {adj }}{ }\right)$ for regression models had predicted yields from climatic data in the 8 growing regions. Thus, the best fitting equations between climate variables and yield anomalies for all regions could be described by the multiple equations as following in Table 2 .

The highest value of $\mathrm{R}^{2}\left(0.468^{* *}\right)$ was observed in $\mathrm{CP}$ which was highly correlated between yield anomaly with the trends of Tmax and Tmin. The two climate variables deemed most suitable for RN. However, the study found that all parameters showed the highest of $\mathrm{R}^{2}$ values which had no significant difference $(\mathrm{P}>0.05)$ between Tmax and ppt with yield anomaly $\left(R^{2}=0.152\right)$. However, a highly significant difference was found in NS $\left(\mathrm{R}^{2}=0.579 * * *\right)$. Although there was obvious $\mathrm{RH}$ trend in $\mathrm{ST}\left(\mathrm{R}^{2}=0.204^{*}\right)$, $\mathrm{RH}$ was not 

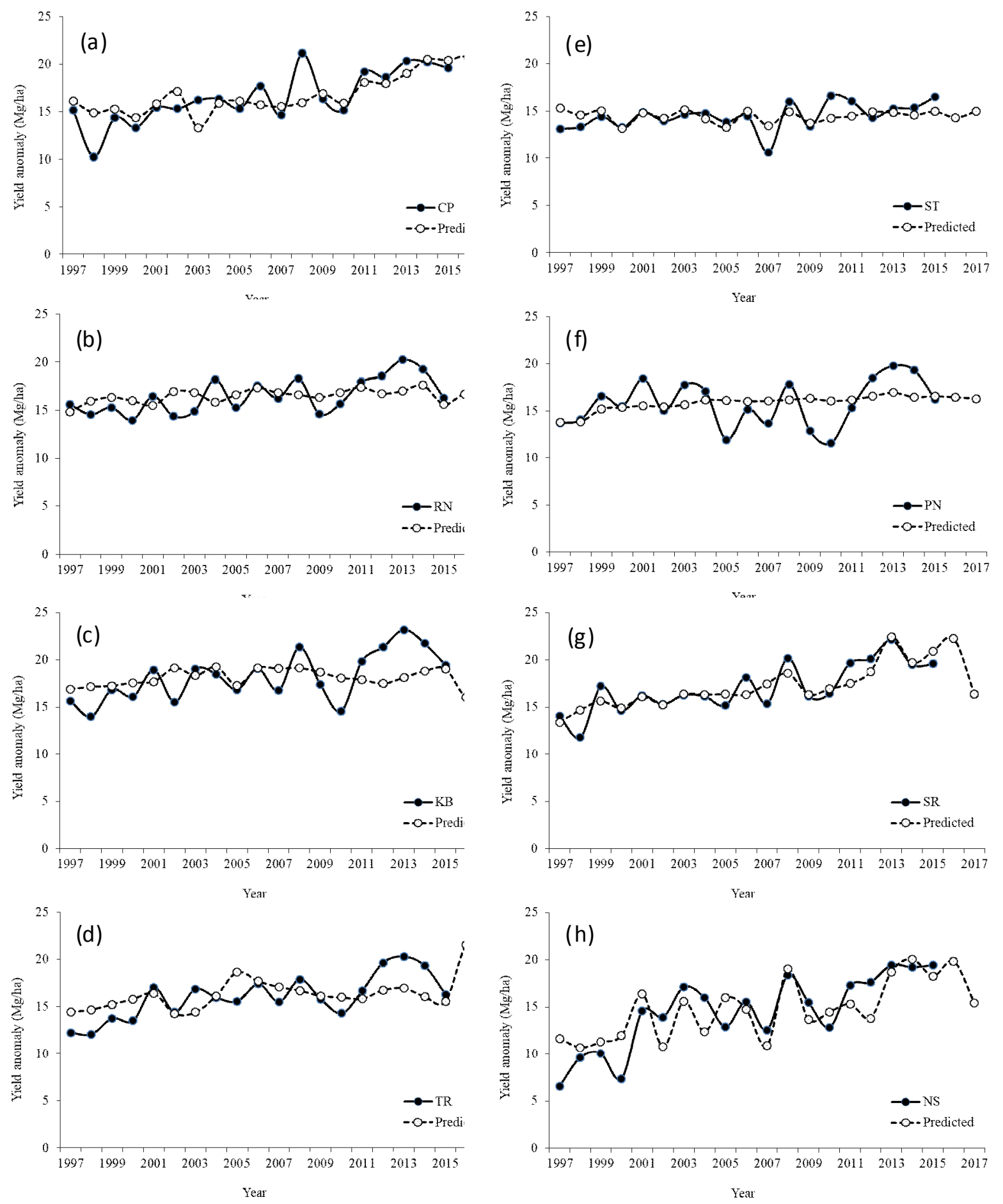

Fig. 3: Relationship between observed and estimated variations of oil palm yields in the 8 different oil palm regions (a-h) (Chumphon; CP, Ranong; RN, Krabi; KB, Trang; TR, Satun; ST, Phang-Nga; PN, Surat Thani; SR, Nakhon Si Thammarat; NS) in southern Thailand from years 1997-2017.

significantly related to yield anomaly in $\mathrm{KB}\left(\mathrm{R}^{2}=0.098\right)$. Meanwhile, the $\mathrm{R}^{2}$ values of Tmax, Tmin and ET in SR were detected the significantly highest correlation $\left(\mathrm{R}^{2}=0.735^{* * *}\right)$ among the other regions.

\section{Time series of oil palm yield trends}

For all oil palm-growing regions, the relationships between observed and estimated yield anomalies showed the total of annual yields which varied with the ranges 
Table 1: The coefficients of determination $\left(\mathrm{R}^{2}\right)$ of maximum temperature $\left(\mathrm{t}_{\max }\right)$, minimum temperature $\left(\mathrm{t}_{\min }\right)$, mean temperature $\left(\mathrm{T}_{\text {mean }}\right)$, rainfall (ppt), evapotranspiration (ET) and relative humidity $(\mathrm{RH})$ in the 8 major oil palm-growing regions

\begin{tabular}{lllllll}
\hline Provinces & $\mathrm{T}_{\max }$ & $\mathrm{T}_{\min }$ & $\mathrm{T}_{\text {mean }}$ & $\mathrm{ppt}$ & $\mathrm{ET}$ & $\mathrm{RH}$ \\
\hline Chumphon(CP) & 0.008 & $0.363^{* *}$ & 0.026 & $0.220^{*}$ & 0.042 & 0.094 \\
Ranong(RN) & $0.220^{*}$ & 0.006 & $0.367^{* *}$ & 0.034 & 0.079 & $0.244^{* *}$ \\
Krabi(KB) & $0.534^{* *}$ & 0.106 & $0.207^{*}$ & 0.001 & 0.076 & 0.009 \\
Trang(TR) & 0.021 & $0.196^{*}$ & 0.011 & 0.024 & $0.358^{* *}$ & $0.196^{*}$ \\
Satun(ST) & 0.127 & $0.210^{*}$ & 0.083 & 0.045 & $0.523^{* *}$ & 0.025 \\
Phang-Nga (PN) & $0.506^{* *}$ & $0.670^{* *}$ & $0.266^{* *}$ & $0.233^{* *}$ & $0.359^{* *}$ & 0.030 \\
Surat Thani(SR) & 0.067 & $0.392^{* *}$ & $0.254^{* *}$ & 0.016 & $0.618^{* *}$ & $0.636^{* *}$ \\
Nakhon Si & $0.306^{* *}$ & 0.119 & $0.218^{*}$ & 0.067 & $0.612^{* *}$ & $0.315^{* *}$ \\
Thammarat(NS) & & & & & & \\
\hline
\end{tabular}

$*, * *=$ Significant differences by linear regression analysis at $<95 \%$

between 13.31-20.61 $\mathrm{Mg} \mathrm{ha}^{-1}$ (17.78 to $\left.-45.17 \%\right), 14.82-$ $17.60 \mathrm{Mg} \mathrm{ha}^{-1}(15.94$ to $-17.92 \%), 16.05-19.27 \mathrm{Mg} \mathrm{ha}^{-1}$ (21.79 to $-24.27 \%), 14.25-21.55 \mathrm{Mg} \mathrm{ha}^{-1}$ (16.96 to -21.48 $\%), 13.17-15.34 \mathrm{Mg} \mathrm{ha}^{-1}$ (13.97 to $\left.-26.70 \%\right), 13.80-16.47$ (10.85 to $-35.03 \%), 13.42-22.44 \mathrm{Mg} \mathrm{ha}^{-1}$ (10.05 to -24.34 \%) and 10.71-20.08 $\mathrm{Mg} \mathrm{ha}^{-1}$ (22.58 to $-77.31 \%$ ) in CP (Fig.3a), RN (Fig.3b), KB(Fig.3c), TR (Fig. 3d), ST (Fig.3e), PN (Fig.3f), SR(Fig.3g) and NS (Fig.3h), respectively. Accordingly, all graphs showed that there were similar trends between observed and estimated values, in the years 19972015. All growing regions had maintained fairly level yield trends. Meanwhile, the yield prediction has demonstrated decreases since 2015, in CP, KB, SR and NS. However, TR seemed to have lower yield trends.

\section{Climate changes and trends in the major oil palm-growing regions}

The major oil palm-producing regions in Southern Thailand had experienced continuous climate changes over the past 28 years. Firstly, the annual fluctuations of average climate changes (Tmax, Tmin, Tmean, ET, ppt and RH) were exhibited as the similarly fluctuated trends at all 8 locations during 1986-2014. This observation also revealed particularly warm events, in TR, ST and SR based on the average increases of Tmax and Tmin. Although all regions were located in various geographical and climate zones in peninsular of Southern Thailand, the annual climate variations were usually caused by changes in patterns of ocean circulation and atmospheric pressures (Mavi and Tupper, 2004). Secondly, the highest anomaly in temperature was found in the seasons of summer (January to May) and rainy (June to December). There were also very similar warming trends for different regions across Southern Thailand in which the warming trends fluctuated in summer (Sdoodee and Sakdiseata, 2013). Lastly, for monthly ppt, many positive trends were often detected in April, June and July, and negative trends were found in February and May over the last 28 years in all regions. Some slight positive and negative anomalies were shown notably in some regions with more frequent droughts. Meanwhile, some studies had been reported that annual rainfalls had slightly increasing trends in some growing seasons in these provinces. During the 30 -year period, annual rainfall totals significantly increased with the higher annual number of rainy days which their intensity remained unchangeable (Sdoodee, 2007).

Similarly, maximum and minimum temperatures had increased significantly over 30 years in the major grapegrowing regions of China (Chiarawipa et al., 2012). Also, there was an impact that showed a warming trend of $0.38^{\circ} \mathrm{C} /$ decade during the years 1981-2015 in Myanmar(Sein et al., 2018) while the temperature has increased in trend in Malaysia since 1977 (Shanmuganathan and Narayanan, 2012). This is also likely that oil palm growing regions would suffer from more frequent droughts or flooding although these patterns are inconsistent in Southern Thailand (Ruangsri et al., 2015). In addition, changes in rainfall distribution could affect year-to-year variations on the phenology of tropical fruit trees such as leaf flushing, flowering date and harvesting time of tropical fruits (Apiratikorn et al., 2014; Ounlert and Sdoodee, 2015), including rubber productivity (Ruangsri et al., 2015) in Southern Thailand.

This implied that seasonal changes were also apparent 
Table 2: Results obtained from the multiple equations between climate variables and yield anomalies for all regions

\begin{tabular}{llll}
\hline Provinces & Equations & $\mathrm{R}^{2}$ & Adjusted $^{2}$ \\
\hline Chumphon $(\mathrm{CP})$ & $\mathrm{Y}=-626.679\left(\mathrm{t}_{\max }\right)+1104.154\left(\mathrm{t}_{\min }\right)-3010.77$ & $0.468^{* *}$ & 0.401 \\
Ranong $(\mathrm{RN})$ & $\mathrm{Y}=-267.656\left(\mathrm{t}_{\max }\right)-2.592(\mathrm{ppt})+12145.26$ & 0.152 & 0.046 \\
Krabi $(\mathrm{KB})$ & $\mathrm{Y}=-150.508(\mathrm{RH})+14900.79$ & 0.098 & 0.045 \\
Trang(TR) & $\mathrm{Y}=128.76(\mathrm{RH})-7588.30$ & $0.242^{*}$ & 0.198 \\
Satun(ST) & $\mathrm{Y}=4.435(\mathrm{ppt})+1433.94$ & $0.204^{*}$ & 0.157 \\
Phang-Nga(PN) & $\mathrm{Y}=254.085\left(\mathrm{t}_{\min }\right)-3461.49$ & 0.115 & 0.063 \\
Surat Thani $(\mathrm{SR})$ & $\mathrm{Y}=633.367\left(\mathrm{t}_{\max }\right)+891.534\left(\mathrm{t}_{\min }\right)-915.369(\mathrm{ET})-34826.90$ & $0.735^{* * *}$ & 0.682 \\
Nakhon Si & $\mathrm{Y}=1054.433\left(\mathrm{t}_{\max }\right)+12.782(\mathrm{ppt})-34467.00$ & $0.579^{* * *}$ & 0.527 \\
Thammarat(NS) & & & \\
\hline
\end{tabular}

$*, * *, * * *=$ Significant differences by multiple regression analysis at $<95 \%$

in rainfall patterns. There was otherwise the low relationship between rainfall and oil palm yield in this study which showed very small increasing trends in rainfalls between 1986 and 2014. Moreover, climate change could lead to seasonal rainfall changes of about $12-20 \%$ per decade with seeing extreme low and high rainfall occurring increasingly often that significantly affected by El Niño-Southern Oscillation (ENSO) (Limsakul and Singhruck, 2016). The extreme environmental stress may thus cause responses in the long term productivity in oil palm plantations in the future scenario. It is likely that oil palm could face prolonged high air temperature, relative humidity and rainy days which could affect fruit bunch development or may cause the oil compounds (Unjan et al., 2017). Therefore, climate variability in some oil palm-growing areas is a good indicator to be considered as one of the impacts of causing climate fluctuations in oil palm yield variations in Southern Thailand.

\section{Climate change patterns and oil palm yield variation}

Oil palms have experienced exceptionally hightemperature trends. The results of this study show that climate and oil palm yields are highly related to each region. These climate data have shown that oil palms exposed to temperature consistently around $3500-3800^{\circ} \mathrm{C}(\mathrm{HI}), 240$ $360 \mathrm{~mm}$ for DI and $21-26^{\circ} \mathrm{C}$ for night temperature (CI). This relationship suggests a significant positive pattern of annual yield anomalies for years 1986-2014. Similarly, all stages of crop plants development are sensitive to temperature, and this is the importance for controlling crop development. However, the rising temperature will diminish the yields of some crops, especially if night temperatures are increased.

Interestingly, the warming trends for the growing season had profoundly influenced oil palm yields for each region in particular by Tmax and Tmin. Meanwhile, for the other regions, there was merely a significant correlation between ppt and yield variation in ST even though the relationship between ppt and yield anomaly was insignificant. Moreover, the analysis on yield variation at growing region showed a substantial inconsistency in yield responses to climate variables for ppt, especially. Most climate variables deemed important for model development for appropriate predictor variables. Thus, two or three climate variables (Tmax, Tmin and ppt) were often highly correlated with yield variation (Lobell et al., 2007) because both temperature and rainfall were critical for optimal growth, inflorescence, and bunch development (Corley and Tinker, 2003). The effect of rainfall pattern was also inextricably linked with soil moisture, soil temperature, and soil respiration which these had been used for estimating evapotranspiration in plantation for the flowering and ripening periods of date palm (Alihouri and Torahi, 2013), coconut (Samanta et al., 2013), and oil palm (Mhanhmad et al., 2011). Furthermore, a high level of water stress for palm trees in Malaysia could be found when El Niño occurred in the Pacific Ocean because of rainfall reduced but air temperature increased (Shanmuganathan and Narayanan, 2012). Therefore, this observation suggests that recent growing season changes in particular for temperatures have already occurred in patterns of yield variables in some oil palm-growing regions in Southern Thailand.

Of all climate variables, Tmin seemed to have the most profound effect on yield anomaly in particular for the temperature during the growing season which trends had 
exhibited both positive and negative tendencies. Also, the best-fit yield model by the high correlation coefficient between observed yield and estimated yield were found at all of the major regions. Despite decision making by the substantial uncertainty of yield in response to climate variables, this observation of oil palm yield in response to temperature, evapotranspiration, rainfall and relative humidity was well assessed by statistical model to directly estimate yield changes in SR, NS and CP, based on the values of $\mathrm{R}^{2}$ and $\mathrm{R}_{\text {adj }}^{2}$ for the multiple regression models.

Meanwhile, oil palm is likely to be sensitive to yield increases in high temperature. Also, increasing minimum temperatures could have an impact on yield, including some tropical crops such as cocoa and rubber (Zhao et al., 2005). On the basis of eco-physiological responses of oil palms, this study indicates that recent climate trends are likely to have more impact on oil palm production of several major producing regions in Southern Thailand. Increasing temperatures and changes in weather are the indicators for climate change in different regions in Peninsular. Moreover, the statistical models of seasonal climate variables of Tmax, Tmin and ppt show potential for yield estimation purposes and should be used for estimating oil palm yield for the future climate change scenarios in Thailand between observed and estimated yield anomalies in all regions, relatively. Interestingly, the method in historical climate data analysis can be applied for estimating seasonal climate effects on oil palm yield anomalies at all major growing regions over the past 28 years. This study may also reflect the significant impact of the temperature range of oil palmgrowing season changes as well as weather conditions on oil palm-producing region.

\section{CONCLUSION}

It is reasonable to conclude that changes in climate have affected phenological responses of oil palm trees during the growing seasons. Furthermore, the historical weather information and its trend will be useful for predicting yield as future climate change scenarios. Therefore, a statistical model can effectively estimate oil palm yield under any climate conditions. However, future investigation must include other influencing factors (such as crop water requirement and physiological traits) in order to get a more precise yield prediction under different weather conditions.

\section{ACKNOWLEDGMENTS}

The authors are very thankful to anonymous reviewers for their greatly constructive comments. We are highly indebted to Asst. Prof. Dr. Prawat Wettayaprasit for his valuable comments and suggestions to the original manuscript. Financial support from Prince of Songkla University (Project no. NAT570397S) and Oil Palm Agronomical Research Center: Phase 2, Faculty of Natural Resources is gratefully acknowledged.

\section{REFERENCES}

Alihouri, M. and Torahi A. (2013). Effects of water stress on quantitative and qualitative fruit characteristics of date palm (Phoenix dactylifera L.). Acta Hort., 975: 287 292.

Apiratikorn, S., Sdoodee, S. and Limsakul, A. (2014). Climaterelated changes in tropical-fruit flowering phases in Songkhla province, Southern Thailand. Res. J. Appl. Sci. Eng. Technol., 7: 3150-3158.

Bal, S.K. and Minhas, P.S. (2017). Atmospheric Stressors: Challenges and Coping Strategies. In: "Abiotic Stress Management for ResilientAgriculture".(Eds.P.S. Minhas et al.). pp. 9-50, Springer Nature Singapore Pte. Ltd.

Cadena, M.C., Devis-Morales, A., Pabón, J.D., Málikov, I., Reyna-Moreno, J.A. and Ortiz, J.R. (2006). Relationship between the 1997/98 El Niño and 1999/2001 La Niña events and oil palm tree production in Tumaco, Southwestern Colombia. Adv. Geosci., 6: 195-199.

Chiarawipa, R., Wu, T. and Han, Z.H. (2012). Observed monthly temperature and precipitation trends in the major grapeproducing regions in China. Acta Hort., 931: 79-86.

Chmielewski, F.M., Muller, A. and Bruns, E. (2004). Climate changes and trends in phenology of fruit trees and field cropsin Germany, 1961-2000. Agric. Forest. Meteorol., 121:69-78.

Corley, R.H.V. and Tinker, P.B.H. (2003). “The Oil Palm”. 4th Edition. Blackwell Science Ltd., Oxford.

IndexMundi. (2019). "Palm Oil Production by Country; Year of Estimate: 2019”.

https:// www. indexmundi.com/ agriculture/ ?commodity=palm-oil (Accessed 10 July 2019)

IPCC. (2007). Summary for Policymakers. In: "Climate Change 2007: Impacts, Adaptation and Vulnerability. Contribution of Working Group II to the Fourth Assessment Report of the Intergovernmental Panel on Climate Change". Cambridge University Press, Cambridge, New York. 
Jones, P.D., Raper, S.C.B., Bradley, R.S., Diaz, H.F., Kelly, P.M. andWigley, T.M.L.(1986). Northernhemisphere surface air temperature variations: 1851-1984. J. Clim. Appl. Meteorol., 25: 161-179.

Kumar, K.R., Kumar, K.K. and Pant, G.B. (1994) Diurnal asymmetry of surface temperature trends over India. Geophys. Res. Lett., 21: 677-680.

Lee, S.K. and Dang, T.A. (2018). Evaluating drought events under influence of El-Nino phenomenon: A case study of Mekong delta area, Vietnam. J. Agrometeorol., 20: 275-279.

Limsakul, A., Limjirakan, S. and Sriburi, T. (2010a). Observed changes in dailyrainfall extremes along Thailand's coastal zone. J. Environ. Res., 32: 49-68.

Limsakul, A., Limjirakan, S., Sriburi, T. and Suthamanuswong, B. (2010b). Trends in temperature and its extremes in Thailand. Thai Environ. Eng. J., 25: 9-16.

Limsakul, A. and Singhruck, P.(2016). Long-term trends and variability of total and extreme precipitation in Thailand. Atmos. Res., 169: 301-317.

Liu, Y., Wang, E.L., Yang, X.G. and Wang, J. (2010). Contributions of climatic and crop varietal changes to crop production in the North China Plain, since 1980s. Global Change Biol., 16: 2287-2299.

Lobell, D.B. and Burke, M.B. (2010). On the use of statistical models to predict crop yield responses to climate change. Agric. For. Meteorol., 150: 1443-1452.

Lobell, D.B., Cahill, K.N. and Field, C.B. (2007). Historical effects of temperature and precipitation on California crop yields. Clim. Change, 81: 187-203.

Maracchi, G., Sirotenko, O. and Bindi, M. (2005). Impacts of present and future climate variability on agriculture and forestry in the temperate regions: Europe. Clim. Change, 70: 117-135.

Mavi, H.S. and Tupper, G.J. (2004). “AgrometeorologyPrinciples and Applications of Climate Studies in Agriculture". Food Products Press, New York.

Mhanhmad, S., Leewanich, P., Punsuvon, V., Chanprame, S. and Srinives, P. (2011). Seasonal effects on bunch components and fattyacid composition in Dura oil palm (Elaeis guineensis). Afr. J. Agric. Res., 6: 1835-1843.

Miller-Rushing, A.J. and Inouye, D.W. (2009). Variation in the impact of climate change on flowering phenology and abundance: An examination of two pairs of closely related wildflower species. Am. J. Bot., 96: 1821-1829.

Ministry of the Environment (Japan).(2014). "Climate Change in Southeast Asia". Global Environment Bureau, and Applied MeteorologyResearch Department and Climate Research Department of the Meteorological Agency. Mitsubishi Research Institute, Inc., Tokyo.

Oettli, P., Behera, S.K. and Yamagata, T. (2018). Climate based predictability of oil palm tree yield in Malaysia.Sci. Rep., 8: 2271. doi.org/10.1038/s41598-018-20298-0

Office of Agricultural Economics. (2018). "Information on ThailandAgricultural: Oil palm”.http:/www.oae.go.th (Accessed 29 February 2019)

Ounlert, P. and Sdoodee, S. (2015). The Effects of climatic variability on mangosteen flowering date in southern and eastern of Thailand. Res. J. Appl. Sci.Eng. Technol., 11: 617-622.

Ruangsri, K., Makkaew, K. and Sdoodee, S. (2015). The impact of rainfall fluctuation on days and rubber productivity in Songkhla province. Int. J. Agric. Tech., 11: 181-191.

Salinger, M.J. (2005) Climate variability and change: Past, present and future-an overview. Clim. Change, 70: 929.

Samanta, M.K., Chattopadhyay, N., Hore, J.K. and Alam, K. (2013). Associationship of weather parameters on the floral characteristics of coconut. Acta Hort., 975: 365 372 .

Sdoodee, S. (2007). The influence of global warming on phenological change of mangosteen (Garcinia mangostana L.) in Songkhla. In: The $33^{\text {rd }}$ Congress on Science \& Technology, Thailand (STT33) “Science \& Technology for Global Sustainability, 18-20 October 2007, Nakhon Si Thammarat. 3pp.

Sdoodee, S. and Sakdiseata, N. (2013). The impact of summer rainfall on alternate bearing of mangosteen (Garcinia mangostana L.) in Southern Thailand. Acta Hort., 975: 373-378.

Sein, K.K., Chidthaisong, A. and Oo, K.L. (2018). Observed trends and changes in temperature and precipitation extreme indices over Myanmar. Atmosphere, 9: 477. doi.org/10.3390/atmos9120477

Shanmuganathan, S. and Narayanan, A. (2012). Modelling the climate change effects on Malaysia's oil palm yield. Conference: E-Learning, E-Management and EServices (IS3e), IEEE Symposium, Kuala Lumpur, Malaysia 21-24 October 2012. doi: 10.1109/ 
IS3e.2012.6414948

Sivakumar, M.V.K., Das, H.P. and Brunini, O. (2005). Impacts of present and future climate variability and change on agriculture and forestry in the arid and semi-arid tropics. Clim. Change, 70: 31-72.

Tao, F.L., Yokozawa, M., Xu, Y.L., Hayashi, Y. and Zhang, Z. (2006). Climate changes and trends in phenology and yields of field crops in China, 1981-2000. Agric. For. Meteorol., 138: 82-92.

Tonietto, J. and Carbonneau, A. (2004). Amulticriteria climatic classification system for grape-growing regions worldwide. Agric. For. Meteorol., 124: 81-97.

Unjan, R., Nissapa, A. and Chiarawipa, R. (2017). Climatic considerations which support the choice between natural rubber and oil palm in Nakorn Si Thammarat, southern Thailand. Kasetsart J. Soc. Sci., 38: 273-281.

Zhao, Y.X., Wang, C.Y., Wang, S.L. and Tibig, L.V. (2005). Impacts of present and future climate variability on agriculture and forestry in the humid and sub-humid tropics. Clim. Change, 70: 73-116. 